\title{
Measuring sexual function in community surveys: Development of a conceptual framework
}

\begin{abstract}
Among the many psychometric measures of sexual (dys)function, none is entirely suited to use in community surveys. Faced with the need to include a brief and non-intrusive measure of sexual function to a general population survey, we developed a new measure. We present findings from qualitative research with men and women in the community designed to inform the conceptual framework for this measure. We conducted 32 semi-structured interviews with individuals recruited from a general practice, an HIV/AIDS charity and a sexual problems clinic. From their accounts we identified 31 potential criteria of a functional sex life. Using evidence from our qualitative data and the existing literature, and applying a set of decision rules, the list was reduced to 13 (eight for those not in a relationship) and a further eight criteria were added to enable individuals to self-rate their level of function and indicate the severity of difficulties. These criteria constitute a conceptual framework that is grounded in participant perceptions; is relevant to all regardless of sexual experience or orientation; provides opportunity to state the degree of associated distress; and incorporates relational, psychological and physiological aspects. It provides the conceptual basis for a concise and acceptable measure of sexual function.
\end{abstract}

\section{Introduction}

Asking questions about sexual function in community surveys is challenging. This is partly because the parameters set by the research context are demanding. They include the need to minimise respondent burden; to ensure acceptability (Dunn, Jordan, Croft, \& Assendelft, 2002); and to ensure relevance to diverse sections of the population. Where sexual function is measured within a larger questionnaire survey covering other aspects of health, brevity is vital; space often permits only one question per difficulty (Hayes \& Dennerstein, 2005). Measures of sensitive behaviours have potential to seem intrusive and even offensive (Loewnthal, 2001), particularly where they may be unexpected, as in a general health survey. The challenge is to achieve a balance between accuracy and acceptability. Community-based measures should also have public health utility, providing useful information on the likely burden of ill health and an indication of how many and who might require professional help. As far as possible, they should avoid including those with transient difficulties and those whose sexual difficulties represent an adaptive response to their particular situation.

The survey team of the [text omitted for blinding] sought a measure of sexual function that covered the key domains and could be completed by all, regardless of gender, sexual orientation, recent sexual experience and relationship status. It needed to be brief (less than 20 items), acceptable, have public health utility and ideally, be informed by the perceptions and experiences of men and women themselves.

We reviewed 54 psychometric measures but did not find one that met our specific needs [ref omitted for blinding]. For example, of three validated measures with male and female versions, two were too long (the GRISS (Rust \& Golombok, (1985)) and the DISF-SR (Derogatis, 1997)), 
one was relevant only to couples in heterosexual relationships (the GRISS), and one omitted key domains and asked about function only over the past week (the ASEX) (Mcgahuey et al., 2000)). An inferior but tolerable option was to use a different measure for men and women. Among the extensively validated female measures, the FSFI (Rosen et al., 2000) is fairly brief (19 items) but does not measure the degree of personal unease related to symptoms. Among the extensively validated male measures, the IIEF (Rosen et al., 1997) is sufficiently brief (11 items) but is focused on erectile function, may be considered intrusive by a general population sample (e.g. 'how often were your erections hard enough for penetration?') is unsuitable for gay men, and does not ask about the degree of personal unease related to symptoms. In general, many measures are unsuited to community surveys because they have been designed as end points in clinical trials and so tend to focus on biomedical aspects of sexual dysfunction (Corona, Jannini \& Maggi, 2006), often to the neglect of relational and subjective aspects of the sexual experience. Finally, few of the existing validated measures have followed US Food and Drug Administration (FDA) guidelines about involving patients in their development (Dennerstein, 2010).

Having not found a suitable measure, we embarked on a programme of development work to produce a tailor-made measure from first principles. A crucial first step was to identify the criteria that should be included within the construct of sexual function. An overriding concern was to ensure that the conceptual framework for the measure would reflect both biomedical and psychosocial perspectives, and would take account of the meaning and significance of sexual function for men and women themselves. In this paper we describe the research that generated the conceptual framework upon which the measure was designed. Elsewhere we describe the psychometric development and validation of the subsequent measure (manuscript under submission).

\section{Methods}

We carried out qualitative research aimed at exploring the meaning of sexual function in the context of the every day lives of men and women. A literature review guided selection of discussion points for interviews and eventual decisions about inclusion or exclusion of elements in the conceptual framework.

\section{Sampling strategy}

Maximum variation sampling was used to include a wide range of sexual function experience. This was achieved by purposefully recruiting three groups of participants:

1) Those who self-identified as having sexual difficulties (consecutive patients attending a National Health Service (NHS) sexual problems clinic in London; $n=6$;);

2) Those with conditions associated with sexual difficulties (individuals with diabetes and depression selected randomly from the diabetes patient list and depression patient list of a General Practitioner (GP) clinic in London and invited to participate by letter $(n=13)$; and individuals with HIV, selected via snowballing techniques from an HIV charity in a regional town $(n=3)$ );

3) A community group of consecutive attendees at the same GP surgery, recruited from the 
waiting room by the first author $(n=10)$.

The first group comprised those with experience of sexual difficulties for which they had sought help; the second group comprised individuals who, because of underlying health problems (diabetes, depression and HIV), might be expected to be experiencing some problems but had not necessarily sought help for them or self-identified as having difficulties (sub-clinical); the third group represented a proxy to a general population sample, with some individuals experiencing difficulties and others not. Non-English speakers and those under the age of 18 were excluded from the sample. Fieldwork was brought to an end when subsequent interviews began to yield little in the way of new information (saturation point).

\section{Data collection}

Interviews were framed by a topic guide that sought to facilitate disclosure of personal experiences. Open-ended questions probed the range of criteria used by participants in assessing their sex lives and what they saw as problematic and non-problematic for themselves (see box one). Detailed probing encouraged participants to describe and explain the criteria they considered important. For those who described any sexual concern or problem $(n=25)$, further discussion sought to explore the impact of that problem on their lives.

Box 1. Interview Topic Guide (excerpt)

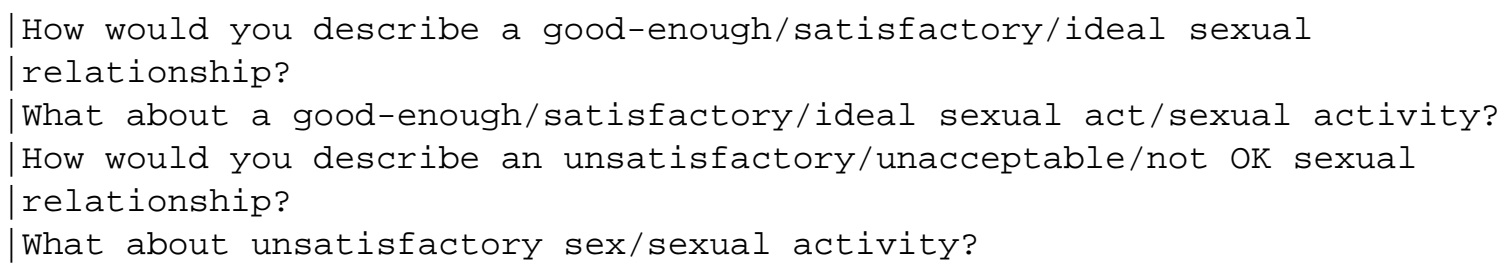

Interviews were undertaken by [first author] (30 interviews) and [second author] ( 2 interviews), and lasted between 45 minutes and two hours. Interviews were recorded (with permission) and transcribed verbatim. Participants signed an informed consent form prior to interview.

Use of the term 'sexual function' was avoided during interviews so as to make no assumptions of its meaning for participants. Instead we offered several plain-language terms (satisfactory/OK for you/ideal/good-enough) and asked participants to think in terms of what was realistic rather than ideal.

\section{Analysis}

Interview transcripts were read and checked as part of the familiarisation process. They were then read again and catalogued according to broad themes (such as orgasm, satisfaction and frequency) and entered into an Excel spreadsheet which served as a data retrieval tool.

As described previously (Mitchell, 2010; Mitchell, 2011), Close examination of the narrative provided by each individual enabled participants to be categorised according to their experience of sexual difficulties (see Table One). Individuals who described no significant frustration or difficulty were categorised as 'functional'; those who expressed minor frustrations and/or difficulties but no significant concern about these experiences were categorised as 'dissatisfied'; 
and those who described significant problem(s), some level of distress and had also either sought or considered clinical help were categorised as 'problematic'.

Once the data had been mapped, the analysis moved to an interpretative phase, drawing on principles of Grounded Theory (Strauss, 1987; Charmaz, 2006). This is an analytical approach particularly suited to generating dense theoretical accounts grounded in data (Green \& Thorogood, 2009). We read the transcripts once more, undertaking line-by-line analysis (or open coding) to identify potential criteria of functional sex; we then used axial coding to explore dimensions of these criteria and relationships between them (see Strauss, 1987). For example, we identified dimensions of the criterion of compatibility as: sexual role/identity, preference for sexual activities, and motive for sex. Throughout, we sought data (quotes/text) that would both confirm and challenge our emerging list of criteria. It was not possible to double code the transcripts but reliability was enhanced via discussion between authors, both of whom are experienced qualitative researchers.

Table 1. Characteristics of the Interviewees (n=32) (reproduced from Mitchell, 2010 and Mitchell, 2011)

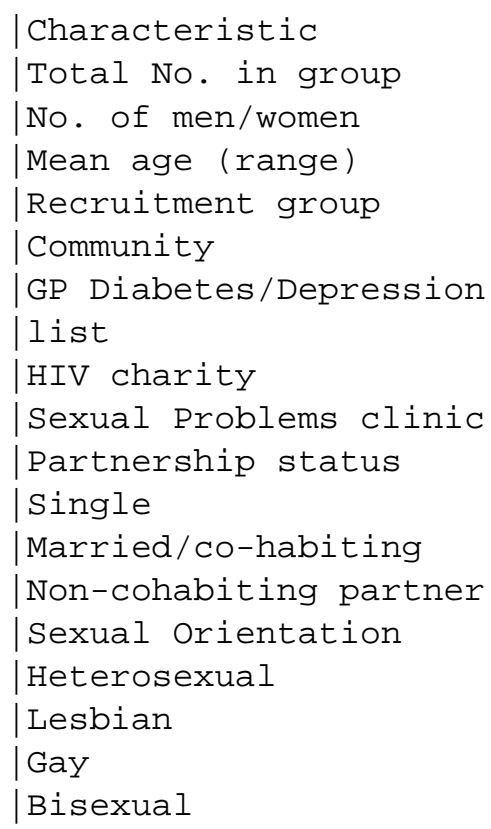

\begin{tabular}{|c|c|c|}
\hline $\begin{array}{l}\text { Functional } \\
7\end{array}$ & $\begin{array}{l}\text { Dissatisfied } \\
9\end{array}$ & $\begin{array}{l}\text { Problematic } \\
16\end{array}$ \\
\hline $2 / 5$ & $3 / 6$ & $10 / 6$ \\
\hline $38.7(23-62)$ & $52.1 \quad(31-78)$ & $52.8(33-70)$ \\
\hline 4 & 4 & 2 \\
\hline 3 & 3 & 17 \\
\hline- & 2 & | 1 \\
\hline- & |- & $\mid 6$ \\
\hline 2 & 5 & 5 \\
\hline 4 & 4 & 9 \\
\hline 1 & - & 2 \\
\hline 7 & $\mid 5$ & | 15 \\
\hline - & | 1 & |- \\
\hline- & $\mid 2$ & | 1 \\
\hline - & $\mid 1$ & |- \\
\hline
\end{tabular}

\section{Literature review}

Prior to and during fieldwork we undertook a comprehensive review of the literature, including a review of measures of sexual dysfunction. We searched key databases - Pubmed; BIDS; Psychinfo, Medline, IBSS and Psych lit - as well as reviewing the reference lists of key articles. We used a range of search terms related to the concept of sexual dysfunction: sexual function/dysfunction, sexual satisfaction/dissatisfaction, sexual function disturbance(s), sexual adjustment. We used the 'OR' operator to include specific terms within this concept (e.g.premature ejaculation and dysparuenia), as well as the AND operator to combine the central concept with terms related to measurement (classif*, measure*, model, psychometric), and with terms related to epidemiology and aetiology (aetiology, prevalence, epidemiol*).

\section{Ethical Approval}


[text omitted for blinding]

\section{Building the conceptual framework}

A conceptual framework outlines a preferred approach to a problem. In our case the purpose of the framework was to describe the phenomenon we were setting out to measure (i.e. sexual function).

We based our framework on the World Health Organisation (WHO) definition of sexual dysfunction: "The various ways in which an individual is unable to participate in a sexual relationship as he or she would wish. Sexual response is a psychosomatic process and both psychological and somatic processes are usually involved." (World Health Organisation, 1992; pg 191). Given that we aimed to develop a population metric rather than clinical measure, we used the term 'sexual function', defining it as the converse of this WHO definition - the capability of an individual to participate in a sexual relationship as he or she would wish.

The development of the framework was guided by our psychosocial perspective and by our inductive approach (deriving criteria from participant accounts). Our review of the literature also urged the adoption of a number of key precepts. These included i) the need to avoid equating vaginal intercourse and sex (Sandfort \& de Keizer, 2001; Boyle, 1993); ii) to view subjective experience and physiological signs as equally valid (Bancroft, Loftus \& Long, 2003; Sugrue \& Whipple, 2001), and iii) to regard the sexual relationship as integral to sexual function (Conaglen, 2001; Tiefer, Hall \& Travis, 2002).

\section{Decision rules to guide the inclusion and exclusion of criteria}

From the outset of the qualitative analysis, it was clear that we would identify more criteria from the data than would be possible to include in the final conceptual framework. To help decide which criteria to keep we set up three decision rules:

1) If two criteria overlap, exclude the criteria for which the evidence is weakest

2) Exclude any criterion that interview respondents regarded as desirable rather than essential.

3) Exclude any criteria that are associated with sexual function, rather than part of the construct itself.

With regard to the third exclusion criteria we defined associated factors as any criteria that could be construed as antecedent to, or an outcome of, a functioning sex life or criteria that were "a degree or so removed from explicit sexual behaviour" (Derogatis, 1997; pg 293); in other words, criteria that represented the context of a sex life (whether personal, relational or physical), or criteria that might be viewed as aetiological agents. The decision was complicated by the fact that the same criterion may be considered part of the construct by some, and an associated factor by others. Whether a criterion belongs within or outside depends on the underlying concept of sexual function. The logic is somewhat circular; the conceptual framework is essentially determined by the criteria incorporated within it, yet the choice of criterion is determined by the underlying 
concept of sexual function.

The decision to exclude or include each criteria was guided by our qualitative data analysis, an examination of the existing literature, and the application of logic.

\section{Results and Discussion}

Through analysis of participant accounts we identified 31 criteria of functional sex. By grouping together conceptually similar criteria, we identified three main aspects of sexual function: psychophysiological; relational; functional sexual self (individual sexuality and ability to have positive sexual experiences); and self-rating/severity. This latter group of criteria measured the severity of problematic sexual experiences, as well as the quality of an overall sex life. We describe each group of criteria in turn, summarising our evidence to support the inclusion or exclusion of criteria within that aspect.

\section{The Psycho-physiological aspect}

We examined the qualitative data to see whether aspects of sex associated with established diagnostic criteria (desire, arousal, orgasm and lack of pain/discomfort) were important to participants. We identified several further psycho-physiological criteria that were also considered important by participants. The evidence and decision for each criterion is summarised in table two.

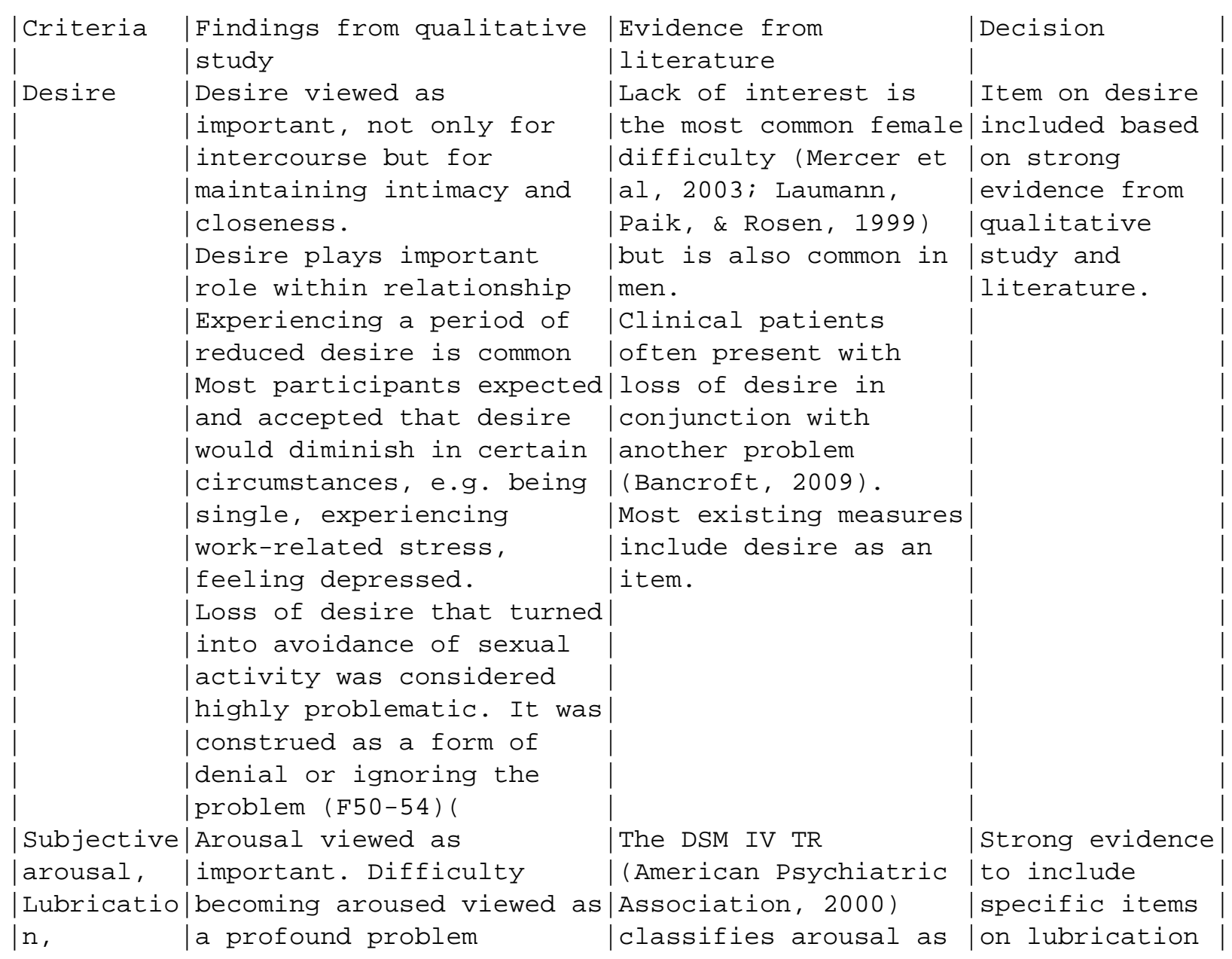




\begin{tabular}{|c|c|c|c|}
\hline Erection & 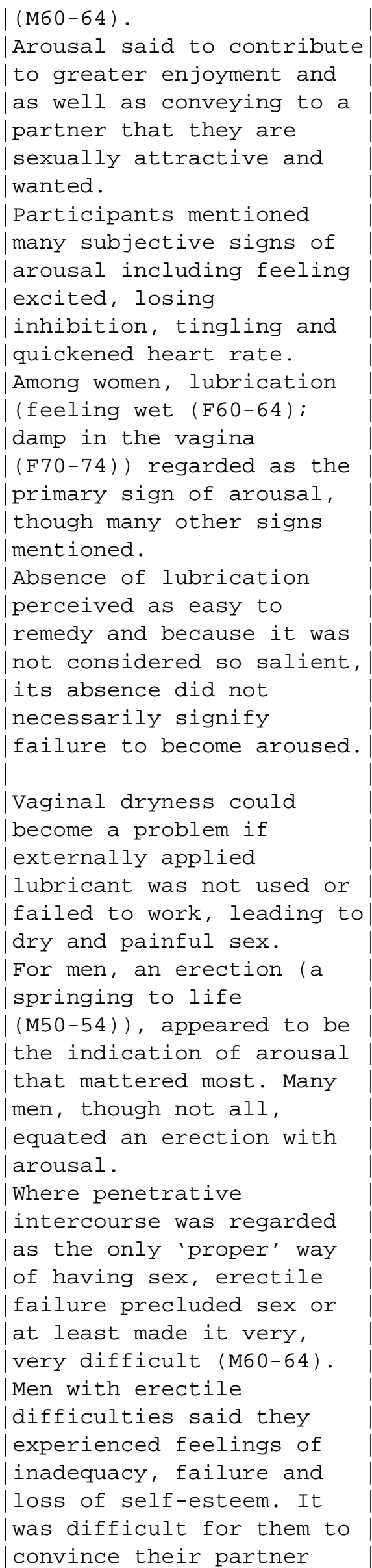 & $\begin{array}{l}\text { erectile disorder for } \\
\text { men and inadequate } \\
\text { lubrication-swelling } \\
\text { |response for women. } \\
\text { | Subjective assessment } \\
\text { of arousal not } \\
\text { |currently included in } \\
\text { |the DSM, though } \\
\text { frequently asked in } \\
\text { measures of sexual } \\
\text { dysfunction, for } \\
\text { example: } \\
\text { the GRISS( (Rust \& } \\
\text { Golombok, 1985) } \\
\text { the BISF-W (Taylor, } \\
\text { Rosen, \& } \\
\mid \text { Leiblum, 1994)). }\end{array}$ & $\begin{array}{l}\text { |and erectile } \\
\text { difficulties. } \\
\text { | Based on } \\
\text { |qualitative } \\
\text { | study, item on } \\
\text { | subjective } \\
\text { |arousal/excitem } \\
\text { |ent included }\end{array}$ \\
\hline
\end{tabular}




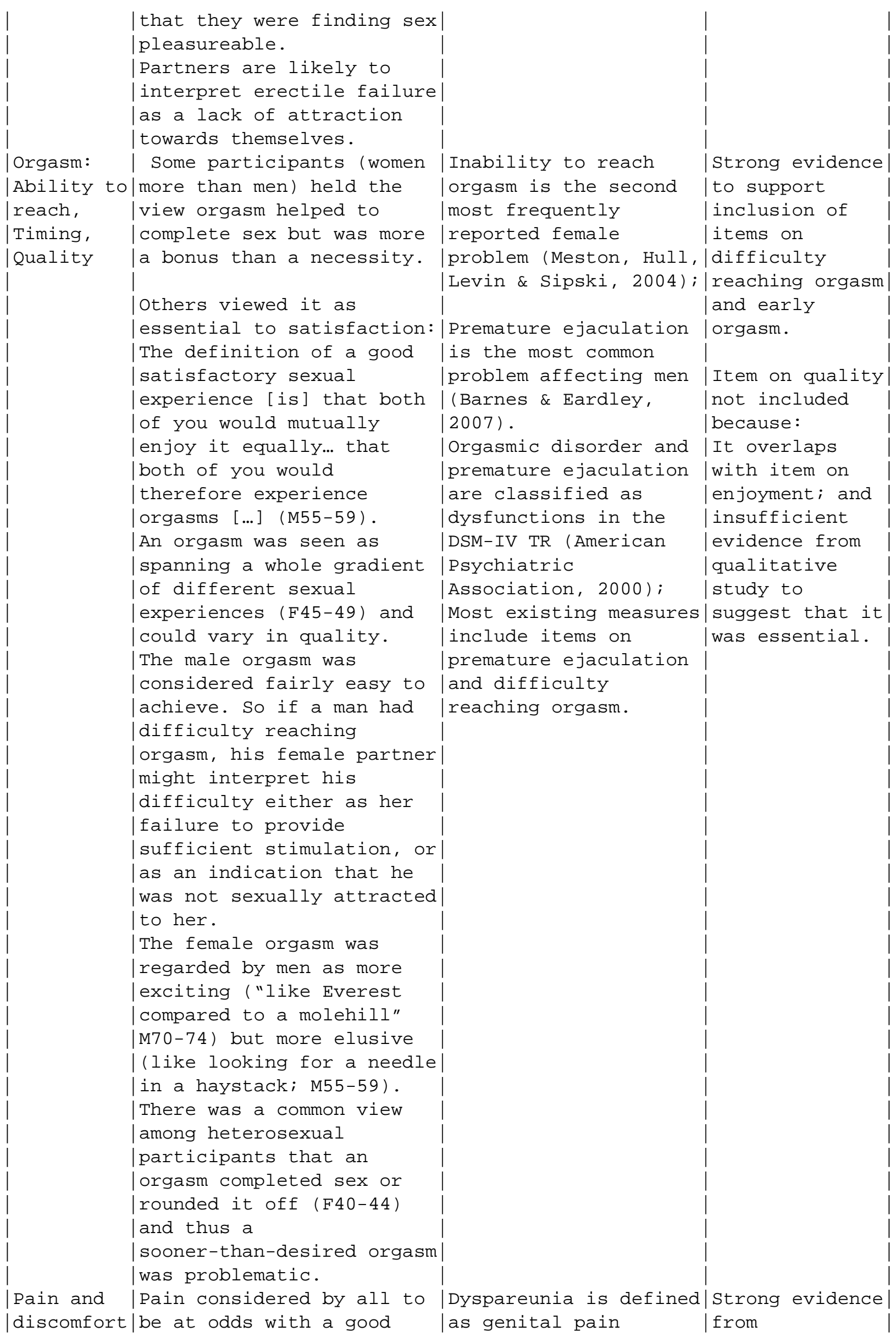


|enough sex life. Most |associated with sexual|qualitative participants felt it would|intercourse in DSM-IV |study and be awful (F20-24) and | American Psychiatric |literature to |distressing (M60-64) to |Association, 2000). | support

|experience a level of pain|Painful intercourse is|inclusion of that precluded sex or |reasonably common |item on pain. |prevented enjoyment. Participants felt that pain might also signal a |Pain is included as an deeper underlying physical|item in several problem in need of attention.

Three participants described pain during intercourse and all had

found it problematic. A woman in her forties with vulvodynia described how constant pain had measures. For example: the GRISS (Golombok \& Rust, 1985)

the SFQ (Quirk,

Heiman, Rosen, Laan, Smith \& Boolell, 2002) the BISF-W (Taylor, dominated her life leading|Rosen, \& Leiblum, directly to depression, (1994))

unemployment and ultimately, the break-up of her relationship.

En joyment Around a third of | participants spontaneously mentioned enjoyment, Satisfacti novelty, excitement, satisfaction or related terms when asked to describe ideal or functional sex. In long-term relationships, maintaining lexcitement was often |regarded as an important challenge.

For several participants with sexual difficulties, a key concern was that they had stopped enjoying sex.

Participants used the term| 'excite' or 'excitement' |variously to describe: a state of arousal (feeling (excited; F42), the experience of orgasm | (crescendo of sexual (excitement; F33), as well as a feeling of attraction | (they find you sexually (exciting; M55).

The term 'satisfaction' was used in a range of |ways: either

|Sexual dissatisfaction| is significantly

associated with physical dysfunction | (Öberg, Fugl-Meyer, \& |Fugl-Meyer, 2004; Dunn, Croft, \& |Hackett, 2000), but it| is still possible to report satisfaction with one's sexual

relationship at the same time as reporting| sexual difficulties (Read, King, \& Watson, (1997) .

|Subjective pleasure is | particularly important | to women (Bancroft, Loftus, \& Long, 2003). Lack of enjoyment often cited a problem by female attendees at sexual problem clinics (Warner, 1987)

Lack of

enjoyment/satisfaction is not currently included in DSM-IV TR (American Psychiatric |Association, 2000),
Items on enjoyment and overall satisfaction included, supported by literature and particularly by qualitative data.

We excluded novelty because| the qualitative data suggested that it was desirable rather than essential. 


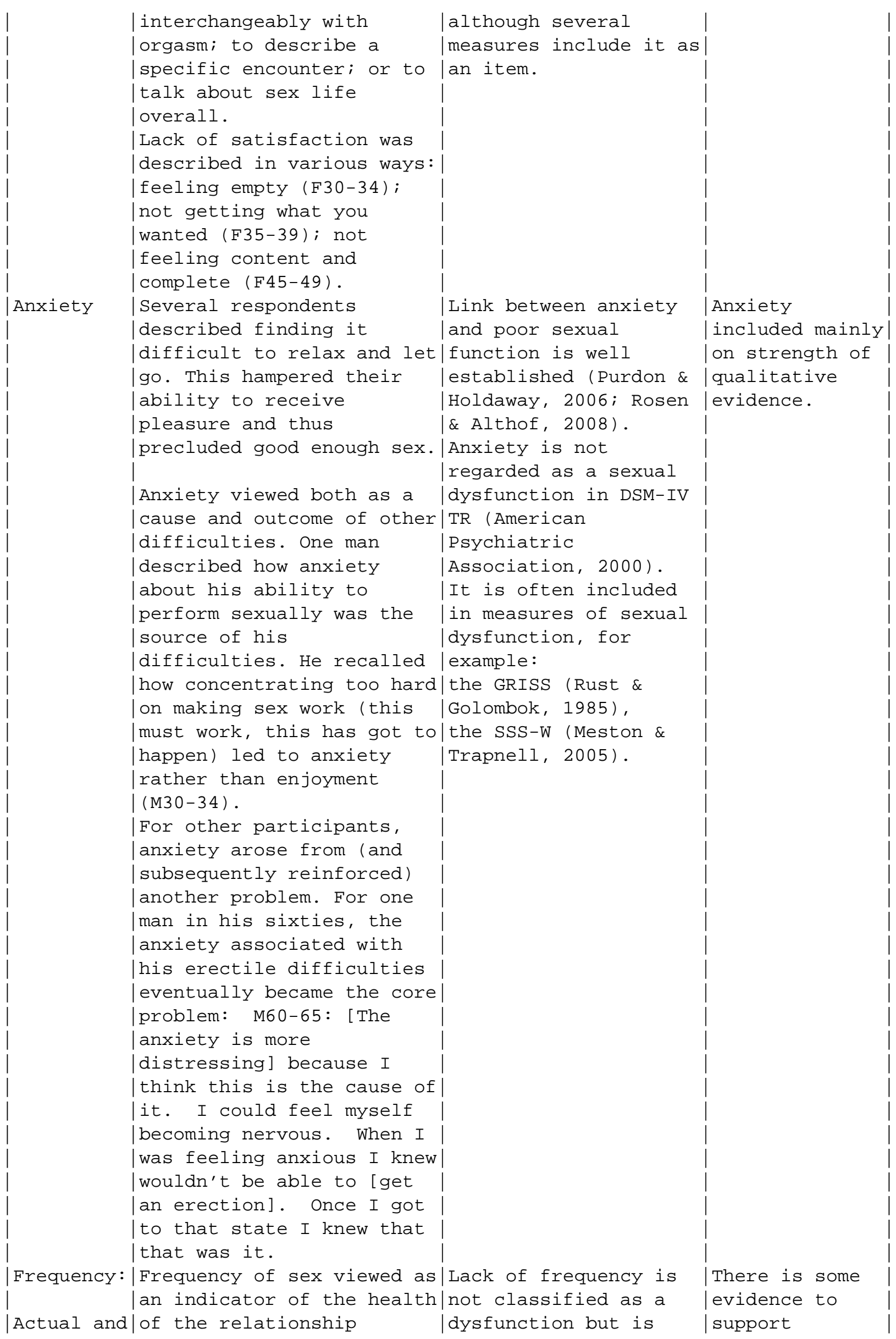




\begin{tabular}{|c|c|c|c|}
\hline $\begin{array}{l}\text { Relative } \\
\text { to desired } \\
\text { level }\end{array}$ & $\begin{array}{l}\text { Regular sex viewed as } \\
\text { important in maintaining } \\
\text { emotional connection and } \\
\text { keeping passion alive } \\
\text { | (M55-59) } \\
\text { Sex less than once a month } \\
\text { | viewed as problematic; an } \\
\text { indication that a } \\
\text { |relationship was going } \\
\text { humdrum very fast } \\
\text { (F30-34) . } \\
\text { Particularly problematic } \\
\text { was an unexplained } \\
\text { decrease in frequency. } \\
\text { Some participants were } \\
\text { concerned about the level } \\
\text { of frequency relative to } \\
\text { what was usual and desired } \\
\text { within a particular } \\
\text { relationship. Others were } \\
\text { concerned about actual } \\
\text { frequency per se. }\end{array}$ & $\begin{array}{l}\text { important to } \\
\text { satisfaction (Smith et } \\
\text { al., 2011). } \\
\text { Frequency can be } \\
\text { affected by factors } \\
\text { such as duration of } \\
\text { the relationship, } \\
\text { fertility intentions } \\
\text { and contraception } \\
\text { (Schneidewind-Skibbe, } \\
\text { Hayes, Koochaki, } \\
\text { Meyer, \& Dennerstein, } \\
\text { 2008). } \\
\text { Items on frequency of } \\
\text { intercourse are often } \\
\text { included in measures } \\
\text { of sexual dysfunction, } \\
\text { e.g.: } \\
\text { the BSFQ (Reynolds et } \\
\text { al., } 1988 \text { ). }\end{array}$ & $\begin{array}{l}\text { inclusion of } \\
\text { frequency but } \\
\text { logically, it } \\
\text { is more } \\
\text { appropriately } \\
\text { |conceptualised } \\
\text { as an outcome } \\
\text { ar correlate of } \\
\text { a functional } \\
\text { sex life }\end{array}$ \\
\hline
\end{tabular}

\section{The Relational Aspect}

Unlike most health behaviours, sex is essentially dyadic in nature. Relationship factors contingent on the sexual partner as well as the interaction between partners - are therefore seen by many as fundamental to the aetiology and experience of sexual difficulties (Dennerstein, Lehert, Burger, \& Dudley, 1999; King, Holt, \& Nazareth, 2007; among others). The current classification systems (DSM-IV TR (American Psychiatric Association, 2000) and ICD-10 (WHO, 1992) do not adequately address the relationship dimension [reference omitted for blinding]. Our qualitative data, supported by the literature, provided strong evidence for the inclusion of a relational dimension. Table three summarises the evidence and decision for each criterion identified in our qualitative study.

\begin{tabular}{|c|c|c|c|}
\hline Criteria & $\begin{array}{l}\text { Findings from qualitative } \\
\text { data }\end{array}$ & $\begin{array}{l}\text { Evidence from } \\
\text { literature }\end{array}$ & |Decision \\
\hline \multirow{12}{*}{$\begin{array}{l}\text { Compatibilit } \\
\text { y: } \\
\text { In motive } \\
\text { In roles } \\
\text { In } \\
\text { preferences }\end{array}$} & Three dimensions of & Among women, & Compatibility in \\
\hline & compatibility were & partner & sexual \\
\hline & identified. & incompatibility is & preferences \\
\hline & |Compatibility in motive & |associated with & | included based \\
\hline & implied wanting sex for the & distress and most & mainly on \\
\hline & same reasons. Participants & of the sexual & qualitative \\
\hline & |perceived a gender & |dysfunctions & |evidence. \\
\hline & disparity with women more & (Witting et al., & \\
\hline & $\begin{array}{l}\text { often motivated by intimacy } \\
\text { |and men more often } \\
\text { |motivated by physical }\end{array}$ & $\begin{array}{l}\text { 2008) } \\
\text { |Compatibility in } \\
\text { preferences or }\end{array}$ & $\begin{array}{l}\text { Compatibility in } \\
\text { |motive for sex, } \\
\text { |and }\end{array}$ \\
\hline & pleasure. & libido types is & compatibility in \\
\hline & roles/identities & self-help guides & roles/identities \\
\hline & |particularly concerned gay & (see Pertot, 2007, & both excluded. \\
\hline
\end{tabular}




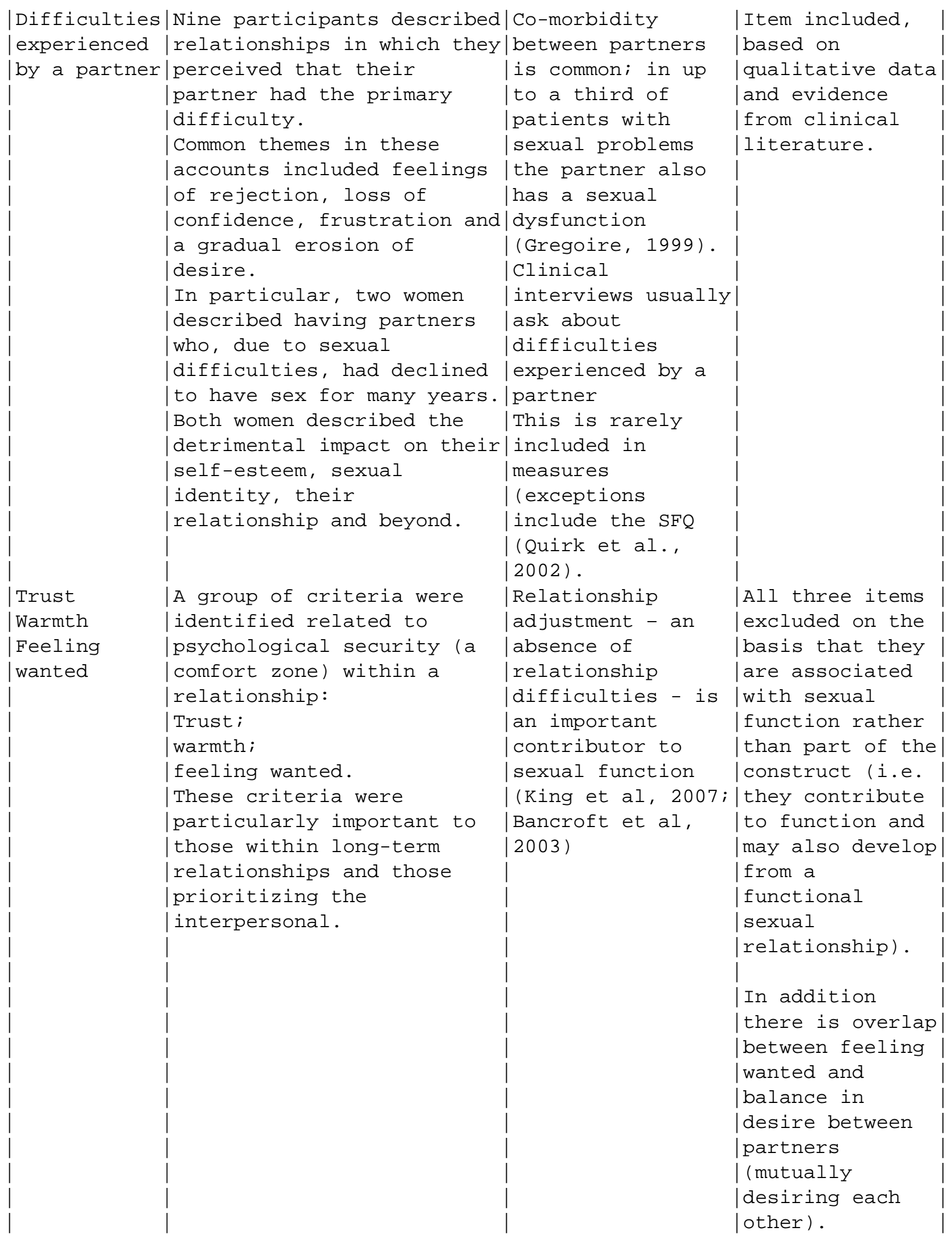

\section{The self-rating and severity aspect}

Given that standard diagnoses correlate only moderately with individual assessment of their situation, particularly for women (King, Holt, \& Nazareth, 2007), and given the need to differentiate transitory difficulties from longer term dysfunction (Mitchell \& Graham, 2008), we 
wanted to ensure that a degree of self-assessment was included in the measure.

From the literature and from our qualitative data, we identified eight potential indicators of severity: duration since onset of symptoms; the frequency with which symptoms occur; level of distress caused by the symptoms; the extent to which an individual perceives that a problem exists; the overall level of distress; whether or not the person has sought professional help; the overall level of satisfaction; and avoidance of sexual activity. The final two were discussed above as potential criteria of the psycho-physiological aspect but we opted to include them here (see table two). We have previously investigated the relative merits and limitations of these indicators [ref omitted for blinding], concluding that there is sufficient evidence to warrant the inclusion of these eight. Later psychometric testing may lead to the exclusion of some from the final measure.

\section{The Functional Sexual-self Aspect}

From our qualitative data, we identified a number of criteria that could be grouped under the dimension, 'functional sexual self'. These criteria related to an individual's sexuality and capacity to enjoy positive sexual experiences. A majority view of sex emerged as an act carrying potential risk of rejection and thus creating feelings of vulnerability. Confidence and comfort therefore emerged as important to good-enough sex. We identified five characteristics of an ideal sexual self related to confidence and comfort: positive body image; ability to give and receive pleasure; positive sexual identity; confidence to communicate needs; and positive motivations to have sex (motivations that are not damaging to the individual or their partner). These can be construed as attributes, attitudes and abilities brought to the sexual encounter, although they might also develop as an outcome of positive sexual experiences.

A second group of criteria relating to 'functional sexual self' clustered around the concept of context, both physical and personal. Key aspects of the personal context were tiredness and stress. Physical context included privacy; a criteria particularly pertinent to those with children living at home.

These criteria are well established in the literature, but are usually examined in terms of their association with sexual dysfunction (see for instance, Sanchez \& Kiefer, 2007; Nazareth, Boynton, \& King, 2003; Rosen \& Althof, 2008; Laumann, Paik, \& Rosen, 1999).

In keeping with the established literature, we excluded all these criteria, assigning them as associated factors (or correlates) rather than part of the construct itself.

\section{The conceptual framework}

The selection process gave rise to a conceptual framework as depicted in table four.

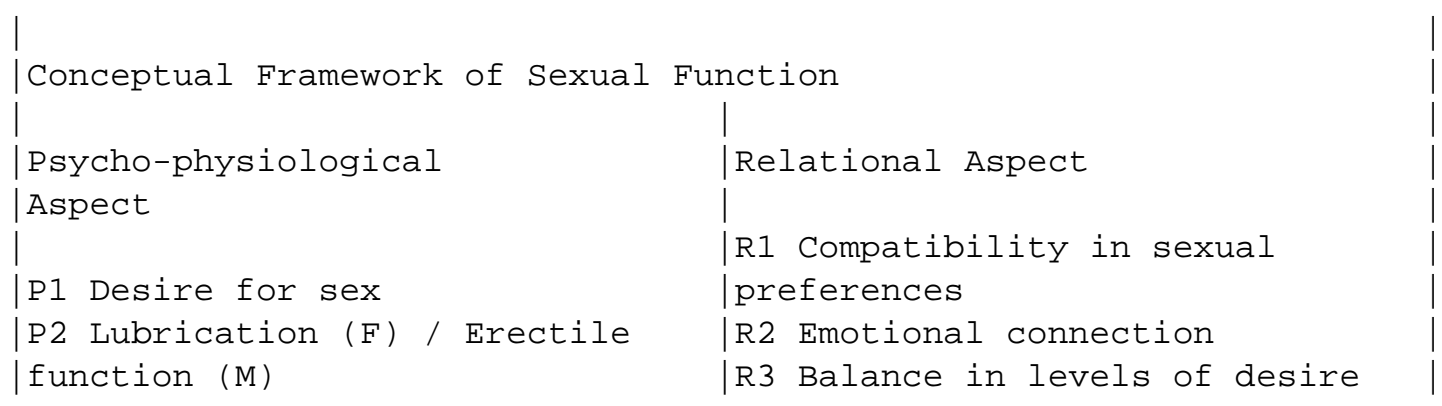




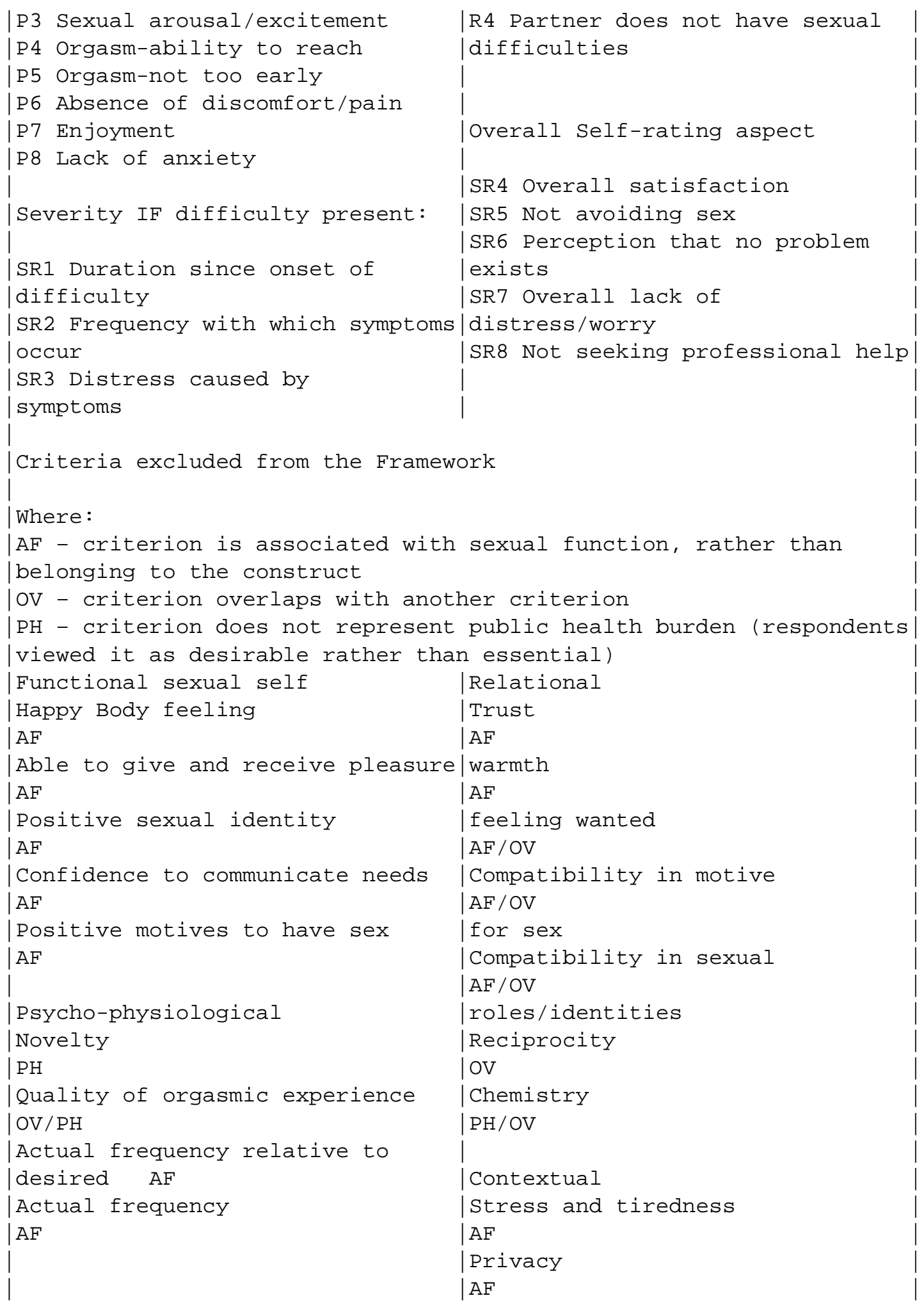

The measure derived from this conceptual framework will be computer-based and will route participants to sections relevant to their experience. Those who have not been in a relationship for the whole of the past year, for example, will be routed past the relationship questions. This means that the measure can be completed by anyone, regardless of their recent sexual experience.

\section{Methodological limitations}


The methodological limitations of our study relate to qualitative approaches more broadly. Qualitative methods are suited to exploring phenomena from the perspectives of others. Semistructured interviews provide rich and detailed descriptions but because the data generated are cumbersome, the sample size is generally small. Sampling is often theoretical rather than probabilistic and so the aim is to generate ideas and concepts that are transferable to other contexts, rather than results that are statistically generalisable to a wider population.

\section{Conclusion}

Our framework is novel in that it is grounded in participant perceptions; provides opportunity for individuals to state the degree to which they see their sex life as problematic; and incorporates relational, psychological and physiological aspects.

The framework provides a solid conceptual basis for a brief and acceptable measure of sexual function, specifically designed for use in community surveys. Just as we identified shortcomings in existing measures, so practitioners with different objectives will see drawbacks to ours. For example, sex therapists might point out that it contains nothing about intimacy in a relationship; experts on premature ejaculation and orgasmic dysfunction (Waldinger \& Schweitzer, 2006a \& b) could consider the number of items on orgasm/ejaculation inadequate for precise measurement; practitioners who advocate on behalf of rare and specific conditions such as persistent sexual arousal disorder (Leiblum \& Nathan, 2001) might point out that these have been omitted; and various individuals (notably The Working Group for a New View of Women's Sexual Problems, 2001) might criticise our attempt to put forward a normative list of difficulties. Whilst some will feel that we have strayed too far from the current classification; others will feel that we have not strayed far enough. In response, we would highlight the fact that most limitations of the measure stem directly from our design imperatives of brevity, user acceptability, relevance to all population sub-groups and public health utility. Furthermore, given the general lack of agreement concerning the conceptualisation and measurement of sexual dysfunction (Balon, 2008; Mitchell \& Graham, 2008), it is simply not possible to meet all expectations. In contrast to many existing measures, we based our decisions on empirical evidence collected specifically for the purpose, thus giving our measure a strong claim to validity. Ultimately the quality and utility of this conceptual framework and subsequent measure will be established by future community-based survey research. 


\section{References}

American Psychiatric Association (2000). Diagnostic and statistical manual of mental disorders, ( $4^{\text {th }}$ ed. DSM-IV-TR). Washington, D.C.: American Psychiatric Association.

Balon, R. (2008). The DSM criteria of sexual dysfunction: Need for a change. Journal of Sex \& Marital Therapy, 34, 186-197.

Bancroft, J., Loftus, J., \& Long, J.S. (2003). Distress about sex: A national survey of women in heterosexual relationships. Archives of Sexual Behavior, 32(3), 193-208.

Bancroft, J. (2009) Human sexuality and its problems. Europe: Elsevier Limited

Barnes, T., \& Eardley, I. (2007). Premature ejaculation: The scope of the problem. Journal of Sex \& Marital Therapy, 33, 151-170.

Boyle, M. (1993). Sexual dysfunction or heterosexual dysfunction? Feminism and Psychology, 3(1), 73-88.

Charmaz, C. (2006). Constructing Grounded Theory: A practical guide through qualitative analysis. London: Sage.

Clement, U. (2002). Sex in long-term relationships: A systemic approach to sexual desire problems. Archives of Sexual Behavior, 31(3), 241-246.

Conaglen, H.M. (2001). Report of the international consensus development conference on female sexual dysfunction: A view from down under. Journal of Sex and Marital Therapy, 27(2), 127-130.

Corona, G., Jannini, E., \& Maggi, M. (2006). Inventories for male and female sexual dysfunctions. International Journal of Impotence Research, 18, 236-250.

Davies, S., Katz, J., \& Jackson, J. (1999). Sexual desire discrepancies: Effects on sexual and relationship satisfaction in heterosexual dating couples. Archives of Sexual Behavior, 28(6), 553-567.

Dennerstein, L., Lehert, P., Burger, H. \& Dudley, E. (1999). Factors affecting sexual functioning of women in the mid-life years. Climacteric, 2, 254-62.

Dennerstein, L. (2010) How changing methods affect our understanding of female sexual function and dysfunction. Journal of Sexual Medicine, 7, 2299-2300

Derogatis, L.R. (1997). The Derogatis Interview for Sexual Functioning (DISF/DISF-SR): An Introductory Report. Journal of Sex \& Marital Therapy, 23(4), 291-304.

Dunn, K.M., Croft, P.R., \& Hackett, G. (2000). Satisfaction in the sex life of a general population sample. Journal of Sex \& Marital Therapy, 26(2), 141-151.

Dunn, K.M., Jordan, K., Croft, P.R., \& Assendelft, W.J. (2002). Systematic review of sexual 
problems: epidemiology and methodology. Journal of Sex and Marital Therapy, 28(5), 399-422.

Green, J., \& Thorogood N. (2009) Qualitative methods for health research. London: Sage Publications.

Gregoire, A. (1999). Assessing and managing male sexual problems. In Tomlinson J. (Ed.), ABC of Sexual Health. London: BMJ Books.

Hayes, R.D., \& Dennerstein, L. (2005). The impact of aging on sexual function and sexual dysfunction in women: a review of population-based studies. Journal of Sexual Medicine, 2, 317-330.

King, M., Holt, V., \& Nazareth, I. (2007). Women's views of their sexual difficulties: Agreement and disagreement with clinical diagnosis. Archives of Sexual Behavior, 36, 281-288.

Laumann, E.O., Paik, A., \& Rosen, R.C. (1999). Sexual dysfunction in the United States:

Prevalence and predictors. Journal of the American Medical Association (JAMA), 281(6), 537-544.

Levine, S.B. (2003). The nature of sexual desire: A clinician's perspective. Archives of Sexual Behavior, 32(3), 279-285.

Leiblum, S.R., \& Nathan, S.G. (2001). Persistent sexual arousal syndrome in women: A newly discovered pattern of female sexuality. Journal of Sex \& Marital Therapy, 27, 365-380.

Mcgahuey, C.A., Gelenberg, A.J., Laukes, C.A., Moreno, F.A., Delgado, P.L., Mcknight, K.M., et al. (2000). The Arizona Sexual Experience Scale (ASEX): Reliability and Validity. Journal of Sex \& Marital Therapy, 26(1), 25-40.

Mercer, C.H., Fenton, K.A., Johnson, A.M., Wellings, K., Macdowall, W., McManus, S., et al.. (2003). sexual function problems and help seeking behaviour in Britain: National probability sample survey. British Medical Journal, 327(7412), 426-427.

Meston, C.M., Hull, E., Levin, R., \& Sipski, M. (2004). Disorders of orgasm in women. Journal of Sexual Medicine, 1, 66-68.

Meston, C.M., \& Trapnell, P.D. (2005). Development and validation of a five-factor sexual satisfaction and distress scale for women: The sexual satisfaction scale for women (SSSW). Journal of Sexual Medicine, 2, 66-81.

Loewenthal, K.M. (2001) An introduction to psychological tests and scales. Philadelphia: Taylor \& Francis Inc.

[ref omitted for blinding]

Mitchell, K., Wellings, K., King, M., Nazareth, I., Mercer, C. \& Johnson, A. (2011) Scripting sexual function. Sociology of Health and Illness, 33(4), 540-553 
Mitchell, K., King, M., Nazareth, I., Wellings, K. (2010) Managing sexual difficulties; A qualitative investigation of coping strategies. Journal of Sex Research, 48(4), 325-333

Mitchell, K.R., \& Graham, C. (2008). Two Challenges for the classification of sexual dysfunction. Journal of Sexual Medicine, 5(7), 1552-1558.

Nazareth, I., Boynton, P., \& King, M. (2003). Problems with sexual function in people attending London general practitioners: Cross sectional study. British Medical Journal, 327(7412), 423-8

Öberg, K., Fugl-Meyer, A.R., \& Fugl-Meyer, K.S. (2004). On categorisation and quantification of women's sexual dysfunctions: An epidemiological approach. International Journal of Impotence Research, 16, 261-269.

Perel, E. (2007) Mating in captivity. Great Britain: HarperCollins Publishers

Pertot, S. (2007). When your sex drives don't match: Discover your libido types to create a mutually satisfying sex life New York: Marlowe and Company.

Purdon, C., \& Holdaway, L. (2006). Non-erotic thoughts: Content and relation to sexual functioning and sexual satisfaction. Journal of Sex Research, 43(2), 154-162.

Quirk, F.H., Heiman, J.R., Rosen, R.C., Laan, E., Smith, M.D., \& Boolell, M. (2002). Development of a sexual function questionnaire for clinical trials of female sexual dysfunction. Journal of Womens Health and Gender Based Medicine, 11(3), 277-289.

Read, S., King, M., \& Watson, J. (1997). Sexual dysfunction in primary medical care: Prevalence, characteristics and detection by the general practitioner. Journal of Public Health Medicine, 19(4), 387-391.

Reynolds, C.F., Frank, E., Thase, M.E., Houck, J., Jennings, R., Howell, J.R., et al. (1988). Assessment of sexual function in depressed, impotent and healthy men: Factor analysis of a brief sexual function questionnaire for men. Psychiatry Research, 24, 231-250.

Rosen, R.C., Riley, A., Wagner, G., Osterloh, I.H., Kirkpatrick, J., \& Mishra, A. (1997). The International Index of Erectile Function (IIEF): A multidimensional scale for assessment of erectile dysfunction. Urology, 49(6), 822-830

Rosen, R.C., \& Althof, S. (2008). Impact of premature ejaculation: The psychological, quality of life, and sexual relationship consequences. Journal of Sexual Medicine, 5(6), 1296-1307.

Rosen, R., Brown, C., Heiman, J., Leiblum, S., Meston, C., Shabsigh, R., et al. (2000). The female sexual function index (FSFI): A multidimensional self-report instrument for the assessment of female sexual function. Journal of Sex \& Marital Therapy, 26(2), 191-208.

Rust, J., \& Golombok, S. (1985). The Golombok Rust inventory of sexual satisfaction (GRISS). 
British Journal of Clinical Psychology, 24 (1), 63-64.

Sanchez, D. T., \& Kiefer, A. K. (2007). Body concerns in and out of the bedroom: Implications for sexual pleasure and problems. Archives of Sexual Behavior, 36(6), 808-820.

Sandfort, T.G.M., \& de Keizer, M. (2001). Sexual problems in gay men: An overview of empirical research Annual Review of Sex Research, 12, 93-120.

Schneidewind-Skibbe, A., Hayes, R.D., Koochaki, P.E., Meyer, J., \& Dennerstein, L. (2008). The frequency of sexual intercourse reported by women: A review of community-based studies and factors limiting their conclusions. Journal of Sexual Medicine, 5, 301-335.

Smith, A., Lyons, A., Ferris, J., Richters, J., Pitts, M., Shelley, J., \& Simpson, J. M.(2011) Sexual and relationship satisfaction among heterosexual men and women: the importance of desired frequency of sex, Journal of Sex \& Marital Therapy, 37(2), 104-115

Strauss, A. (1987). Qualitative analysis for social scientists. New York: Cambridge University Press.

Sugrue, D., \& Whipple, B. (2001). The consensus-based classification of female sexual dysfunction: barriers to universal acceptance. Journal of Sex \& Marital Therapy, 27(2), 221-6.

Taylor, J.F., Rosen, R.C., \& Leiblum, S.R. (1994). Self-Report assessment of female sexual function: Psychometric evaluation of the brief index of sexual function for women. Archives of Sexual Behaviour, 23(6), 627-643.

The Working Group for a New View of Women's Sexual Problems. (2001). A new view of women's sexual problems. In: E. Kaschak \& L. Tiefer (Eds.) A new view of women's sexual problems (pp 1-8). New York: The Haworth Press.

Tiefer, L., Hall, M., \& Travis, C. (2002). Beyond dysfunction: A new view of women's sexual problems. Journal of Sex \& Marital Therapy, 28, 225-232.

Waldinger, M., \& Schweitzer, D. (2006a). Changing paradigms from a historical DSM-III and DSM-IV view: Toward an evidence-based definition of premature ejaculation. Part I validity of DSM-IV-TR. Journal of Sexual Medicine, 3, 682-692.

Waldinger, M., \& Schweitzer, D. (2006b). Changing paradigms from a historical DSM-III and DSM-IV view: Toward an evidence-based definition of premature ejaculation. Part II proposals for DCM-V and ICD-10. Journal of Sexual Medicine, 3, 693-705.

Warner, P., Bancroft, J., members of the Edinburgh Human Sexuality Group (1987) A regional clinical service for sexual problems: a three year survey. Sexual and Marital Therapy, 2, $115-126$

Witting, K., Santtila, P., Varjonen, M., Jern, P., Johansson, A., von der Pahlen, B., et al. (2008) Female sexual dysfunction, sexual distress and compatibility with partner. Archives of Sexual Behaviour, 5, 2587-2599.

World Health Organization. (1992). ICD-10: International Statistical Classification of Diseases 
and Related Health Problems, $10^{\text {th }}$ ed. Geneva: WHO.

Zilbergeld, B., \& Ellison, C.R. (1980). Desire discrepancies and arousal problems in sex therapy. In: S.R. Leiblum \& L.A. Pervin (Eds.) Principles and Practice of Sex Therapy. (pp 66-104) New York: Guilford Press; 1980:66-104 